\title{
PRÁTICAS PEDAGÓGICAS DESENVOLVIDAS NA ESCOLA MULTISSERIADA RIBEIRINHA DA AMAZÔNIA PARAENSE
}

\author{
Hellen do Socorro de Araújo Silva ${ }^{1}$ \\ Luís Carlos Santos Lopes ${ }^{2}$
}

\begin{abstract}
RESUMO
O estudo trata de reflexões teórico-práticas de experiências educativas interdisciplinares desenvolvidas nos anos iniciais de uma escola pública do campo, com objetivo de compreender como as práticas pedagógicas nas turmas multisseriadas nas aulas de História, Geografia e Ciências Naturais têm se materializado de forma interdisciplinar considerando a realidade das comunidades ribeirinhas. A metodologia abordada foi a pesquisa-ação, pois buscou-se a participação ativa do objeto de pesquisa, a vivência e intervenção no contexto escolar. A realidade investigada foi uma turma multisseriada de Ensino Fundamental do 20 ao 50 ano. 0 foco principal esteve voltado para a interdisciplinaridade das temáticas abordadas, assim como ampla discussão sobre as comunidades camponesas no Brasil e na Amazônia, bem como a identidade e o trabalho dos sujeitos. As atividades ocorreram durante o ano de 2018 na Escola Municipal de Ensino Fundamental Fé em Deus, Rio Ana Igarapé, município de Igarapé-Miri, no Estado do Pará. Os resultados revelaram que trabalhar a interdisciplinaridade e a dialogicidade com turmas heterogêneas nas escolas multisseriadas com base nos princípios dos temas geradores freirianos permite ao professor e aos alunos uma dinâmica promissora para o processo de ensino-aprendizagem e ao aprofundamento do conhecimento da realidade social e escolar.
\end{abstract}

Palavras-chave: Interdisciplinaridade. Educação do campo. Educação ribeirinha. Práticas pedagógicas.

PEDAGOGICAL PRACTICES DEVELOPED AT THE RIBEIRINHA AMAZÔNIA PARAENSE MULTISERIES SCHOOL

\section{ABSTRACT}

The study deals with theoretical-practical reflections of interdisciplinary educational experiences developed in the early years of a public school in the countryside. In order to understand how the pedagogical practices in multiserial classes in History, Geography and Natural Sciences classes, they have materialized in an interdisciplinary way considering the reality of riverside communities. The methodology used was action research, as it sought to actively participate in the research object, the experience and intervention in the school context. The investigated reality was a multiseries class of elementary school from the 2 nd to the 5 th year. The main focus was on the interdisciplinarity of the themes addressed, as well as a broad discussion on peasant communities in Brazil and the Amazon, as well as the identity and work of the subjects. The activities took place during the year 2018 at EMEF Fé em Deus, Rio Ana Igarapé, municipality of Igarapé-Miri, in the state of Pará. The results revealed that working with interdisciplinarity and dialogicity with heterogeneous classes in multiseriate schools based on the principles of the themes Freirean generators allow the teacher and students a promising dynamic for the teaching-learning process and for deepening the knowledge of the social and school reality.

Keywords: Interdisciplinarity. Rural education. Riverside education. Pedagogical practices.

Recebido em: $19 / 3 / 2020$

Aceito em: $16 / 4 / 2020$

\footnotetext{
1 Autora correspondente. Universidade Federal do Pará - Faculdade de Educação do Campo - Campus Universitário do Tocantins-Cametá (Ufpa). Trav. Pe. Antônio Franco, 2617 - Bairro da Matinha. CEP 68400-000. Cametá/PA, Brasil. http://lattes.cnpq.br/4932105074922888. https://orcid.org/0000-0002-5443-2373. hellen.ufpa@gmail.com

2 Universidade Federal do Pará - Instituto de Educação Matemática e Científica - IEMCI. Mestrado em Docência em Educação em Ciências e Matemática. Rua Augusto Corrêa, 01 - Guamá, Belém/PA, CEP 66075-110. https://orcid.org/0000-0001-8182-4113. http://lattes.cnpq. br/4163766888940802.
} 
Este texto trata de um estudo realizado acerca das práticas pedagógicas desenvolvidas por professores que atuam nas escolas públicas do campo no Estado do Pará e resulta da investigação desenvolvida vinculada ao curso de Especialização em Práticas Pedagógicas na Educação do Campo e aos estudos ligados à Linha de Pesquisa "Políticas e Sociedades" do Programa de Pós-Graduação em Educação e Cultura (PPGEDUC) da Universidade Federal do Pará, Campus do Tocantins-Cametá no período de 2018 a 2019.

A investigação parte dos indicadores de que as práticas pedagógicas dos professores que atuam nas escolas multisseriadas da Amazônia paraense ainda estão centradas num currículo urbanocêntrico, em condições de funcionamento precárias, com livros didáticos distantes da realidade da Amazônia e frequentes rotatividades de professores das escolas pelo fato de serem contratados, o que dificulta a constituição de vínculos sociais, políticos e culturais com as comunidades dos povos do campo, das águas e das florestas.

Nesse sentido, partimos do princípio de que as práticas pedagógicas das escolas do campo exigem um currículo que respeite "a diversidade do campo em seus aspectos sociais, culturais, ambientais, políticos, econômicos, de gênero, geracional e de raça e etnia" (BRASIL, 2010), demandando outras pedagogias com "tempos/espaços em que outros sujeitos se afirmam, trazendo experiências sociais, políticas de resistências, de construção de outra cidade, outro campo, outros saberes e identidades" (ARROYO, 2014, p. 25).

Diante disso, compreendemos que as práticas pedagógicas "expressam um processo de trabalho que possui intencionalidade e é determinada (podendo determinar) pela prática social e pelo conjunto de relações determinadas na sociedade [...]" (SOUZA, 2016, p. 45). Por isso o trabalho realizado nas escolas e/ou fora delas deve integrar-se à realidade sociocultural, pois os conhecimentos estão conectados e inter-relacionados.

As práticas trabalhadas nas escolas investigadas durante a pesquisa estiveram centradas em temáticas cuja representação foi a relação histórica e reflete uma identidade dos camponeses no Brasil, suas lutas, suas trajetórias, suas organizações e a produção ligada à agricultura familiar. Segundo Vasconcelos e Hage (2017), os povos ribeirinhos vivem e já viveram inúmeras formas de rejeições quanto as suas classes, identidades e territorialidades e por isso devem ter uma formação que os ajude a fortalecer suas identidades e a se organizarem para lutar contra seus opressores. Dessa forma, acreditamos que as práticas pedagógicas devem ser pensadas para promover a autonomia dos alunos ribeirinhos e fortalecer suas identidades como sujeitos do campo.

O trabalho docente nas escolas ribeirinhas deve encontrar-se com práticas pedagógicas voltadas para a formação de cidadãos críticos e emancipados, capazes de ser agentes de transformação em suas localidades, ou seja, desenvolverem ações educativas que possam interagir com o cotidiano sociocultural dos sujeitos para inter-relacionarem trabalho, cultura, identidade e as especificidades dos sujeitos do campo (HAGE, 2018).

A pesquisa teve como objetivo compreender como as práticas pedagógicas nas turmas multisseriadas nas aulas de História, Geografia e Ciências Naturais têm se materializado de forma interdisciplinar considerando a realidade das comunidades ribeirinhas. 
Para alcançar esse objetivo organizamos o processo de ensino e aprendizagem a partir das aulas práticas usando as especificidades de cada comunidade ribeirinha para contribuir na compreensão dos conteúdos. Também buscamos criar uma visão de produção familiar, como eles, em comunidade, mostrando como podem produzir alimentos para consumo próprio, ajudando-os a lidar com problemas sociais, como é o caso da fome, que está presente em grande parte das famílias do campo, assim como também procuramos trabalhar nas práticas pedagógicas a cultura e a identidade camponesa.

Dessa forma este trabalho está estruturado em três momentos. O primeiro constitui-se da metodologia em que destacamos os caminhos teórico-metodológicos da pesquisa. O segundo trata das reflexões acerca das comunidades ribeirinhas e das escolas multisseriadas e no terceiro momento abordamos as práticas pedagógicas nas escolas multisseriadas considerando o trabalho desenvolvido nas áreas de Ciências, História e Geografia na perspectiva interdisciplinar.

\section{METODOLOGIA}

A metodologia desta investigação esteve ancorada na pesquisa, do tipo pesquisa-ação, pois a participação dos sujeitos nela envolvidos é ativa, propondo práticas e soluções para as problemáticas levantadas, Thiollent (1986, p. 14) conceitua a pesquisa-ação como:

A pesquisa-ação é um tipo de pesquisa social com base empírica que é concebida e realizada em estreita associação com uma ação ou com a resolução de um problema coletivo e no qual os pesquisadores e os participantes representativos da situação ou do problema estão envolvidos de modo cooperativo ou participativo.

Desta maneira, com a pesquisa-ação procuramos relacionar empiria e ação para integrar as práticas existentes com as ações dos pesquisadores, a fim de solucionar a problemática com a máxima eficiência por meio de ações transformadoras. Esse tipo de pesquisa é sugerido para a análise de grupos sociais e coletivos (THIOLLENT, 1986).

A pesquisa-ação também é usada para engajamentos e emancipação de grupos sociais tendo um cunho sociopolítico, se dá pela escuta dos envolvidos sem deixar que se sobressaia o interesse particular do pesquisador, com os resultados sendo analisados em conjunto para que haja uma participação ativa dos envolvidos (THIOLLENT, 1986). Assim sendo, destacamos que a pesquisa-ação é uma metodologia que nos orienta a organizar pesquisas sociais de maneira que os participantes se envolvam na situação analisada, havendo um diálogo entre pesquisador e participantes.

As atividades foram desenvolvidas na Escola Municipal de Ensino Fundamental Fé em Deus, anexa da Escola Municipal de Ensino Fundamental Sebastiana Pena Pantoja de Araújo, localizada no Rio Ana Igarapé, no município de Igarapé-Miri, Pará. As atividades foram aplicadas em uma turma multisseriada com 13 alunos do $3^{\circ}$ ano ao $5^{\circ}$ ano do Ensino Fundamental, os quais tinham idades de 8 a 11 anos. As práticas foram escolhidas a partir da observação feita no início do ano letivo de 2018 , levando em consideração as especificidade e cultura da comunidade. 
A abordagem da pesquisa foi qualitativa, pois ela nos permite uma melhor compreensão dos fatos para trabalhar as particularidades e subjetividades, fornecendo dados relevantes e profunda compreensão da realidade (HAGUETTE, 2005).

Foram realizada entrevistas semiestruturadas com quatro pais a partir de um roteiro com seis perguntas, a saber: É importante ensinar sobre o plantar e colher nas salas de aulas? A escola deve trabalhar com as crianças sobre suas origens e identidades? A escola tem se preocupado em ensinar para as crianças do campo que elas são sujeitos de direitos? Trabalha-se com crianças sobre hortas, sementes, cultivo de plantas. Você observou alguma diferença neles quanto a isso? Na sua opinião, o que deveria ser essencial na educação das escolas do campo? Você considera importante trabalhar na escola os conhecimentos socioculturais do local?

Este trabalho foi desenvolvido em três partes principais: a primeira foi o levantamento inicial, quando, em roda de consversa com os alunos, buscou-se conhecer a realidade da comunidade; a segunda foram as práticas pedagógicas trabalhadas a partir dos eixos identidades, heterogeneidade, interdisciplinaridade, dialogicidade e no terceiro momento ocorreu a integração a partir do diálogo com os pais acerca das práticas pedagógicas desenvolvidas em sala de aula.

\section{COMUNIDADES RIBEIRINHAS E AS ESCOLAS MULTISSERIADAS NA AMAZÔNIA PARAENSE}

As comunidades ribeirinhas são formações sociais características da Amazônia, localizadas nos meios rurais em áreas de várzeas. Muitas delas são consideradas cidades ribeirinhas, pelo fato de manterem uma interdependência com as comunidades ribeirinhas. Isso é muito observado em Igarapé-Miri, onde as comunidades ribeirinhas apresentam um grande protagonismo, tanto econômico quanto social (PEREIRA, 2014).

As comunidades ribeirinhas surgiram por estratégias da Coroa Portuguesa com o intuito de povoamento das então províncias do Grão-Pará e Maranhão, desse modo surgindo as primeiras vilas e fortes em pontos estratégicos para a exploração de recursos locais, tanto naturais quanto sociais, decorrendo assim a formação do caboclo. Essas povoações eram também uma forma de resistir aos interesses de outros países em ocupar tais espaços (PEREIRA, 2014).

Os povos ribeirinhos não são apenas uma nova formação de um povo miscigenado de povoamento, mas sim de sujeitos únicos que apresentam uma identidade, cultura, territorialidade, entre outros aspectos que fazem deles únicos (PEREIRA, 2017).

Nesse sentido, a educação do campo é essencial para a construção social do ribeirinho, uma vez que ela busca a sua emancipação, visto que o espaço e as relações de poder estabelecem a identidade e a territorialização dos sujeitos. Assim o trabalho, a identidade, a temporalidade, a memória e a cultura tornam-se fatores crucias na territorialidade ribeirinha, sendo importante manter uma relação estreita entre eles e a educação (OLIVEIRA NETO, 2011).

Sabe-se que as escolas multisseriadas são bastante presentes no campo brasileiro e se fazem características da educação no campo; atualmente essas escolas vêm sendo impactadas por processos de (multi)seriação das turmas, em que tem a série como re- 
ferência, o currículo centrista e a lógica disciplinar que acabam por serem reproduzidas nas escolas multisseriadas. Tais práticas ainda são heranças de uma pedagogia colonial, ensinando-os apenas a exercer o trabalho sob as necessidades do capitalismo, atendendo a um modelo educacional hegemônico e urbanocêntrico, que pouco considera as reais necessidades do campo.

A (multi)seriação se dá quando a escola divide as turmas multisseriadas em grupos por séries escolares, deixando de lado todas as particularidades e especificidades dessas turmas, adotando o modelo urbano de ensino, ou seja, o (multi) representa o vínculo que as escolas multisseriadas ainda apresentam com o modelo seriado de ensino (HAGE, 2014). Esse vínculo se dá, principalmente, por causa da fragmentação, padronização e hierarquização das escolas multisseriadas, sem dar espaço para que as próprias escolas possam construir seus pilares de acordo com suas territorialidades para assumir uma identidade que seja ligada à realidade do campo.

Dessa forma, enfatizamos que é preciso transgredir o paradigma da multisseriação como modelo seriado de ensino, propondo o processo de integração do conhecimento, a interdisciplinaridade e a valorização do coletivo dentro das salas de aula, dando ênfase às especificidades das comunidades onde a escola está inserida, no sentido de valorizar a cultura, identidade e demais aspectos locais.

Nesse sentido, transgredir o modelo seriado de ensino significa reconfigurar a identidade das escolas multisseriadas, pois essa tentativa de fazer a seriação, comparando-se com o ensino das escolas urbanas, acaba gerando um déficit no processo de ensino e de aprendizagem dos alunos, provocando assim as visões negativas sobre a importância das escolas multisseriadas para a Amazônia, concepção esta que desqualifica os sujeitos sociais do campo. Essa generalização se dá pelo fato de ainda se ter uma educação voltada a atender às necessidades do mundo capitalista e não para à emancipação do sujeito e de sua construção social (HAGE, 2014).

Fernandes e Molina (2004) abrem a discussão sobre a construção do paradigma da educação do campo, levando-nos a pensar em uma educação que seja voltada aos interesses e territorialidades dos camponeses. Eles ainda pontuam que, para se quebrar um paradigma é necessário que se encontre resposta para superar o que está imposto. Os autores observam que "os paradigmas são territórios teóricos e políticos que contribuem para transformar a realidade" (FERNANDES; MOLINA, 2004, p. 32). Em consonância com essas reflexões, as Diretrizes Operacionais para Educação Básica nas Escolas do Campo (BRASIL, 2002, p. 1) afirmam que:

Parágrafo único. A identidade da escola do campo é definida pela sua vinculação às questões inerentes à sua realidade, ancorando-se na temporalidade e saberes próprios dos estudantes, na memória coletiva que sinaliza futuros, na rede de ciência e tecnologia disponível na sociedade e nos movimentos sociais em defesa de projetos que associem as soluções exigidas por essas questões à qualidade social da vida coletiva no país.

Dessa forma, apresenta-se como agentes de transformação produzir uma educação com um novo paradigma relacionado à educação do campo, com ênfase nas escolas, que busque superar a visão que Fernandes e Molina (2004) chamam de "visão tradicional do espaço rural" e colocando como princípio o relacionamento do homem 
com o seu meio de vivência. Essa visão do espaço rural impede que as necessidades dos moradores do campo prevaleçam, pois elas se contrapõem aos interesses do capitalismo. Esse paradigma acaba gerando nos indivíduos a visão de exclusão na sociedade, uma vez os próprios sujeitos sentem-se oprimidos pelo sistema.

Dessa forma, precisamos transgredir o paradigma que atualmente se impõe sobre a educação, em especial a ofertada no campo, (re)significando o ensino e buscando por meio da educação trabalhar, não apenas, com a formação acadêmica do aluno, da mesma maneira na formação para a compreensão de seu direito sobre suas terras, trabalho e posição na sociedade, sem que suas identidades, culturas e territorialidades sejam abaladas.

Segundo Hage (2014), as escolas multisseriadas têm sofrido com o fechamento também por conta de visões negativas quanto à qualidade do ensino, casualidade que se dá, na maioria das vezes, por conta da precarização dessas escolas; ainda ressalta que o que também tem contribuído para tais fechamentos são os processos de nucleações, onde as escolas multisseriadas (conhecidas também como isoladas) são remanejadas para aquelas que passaram por processos de nucleação nos territórios rurais.

Algumas dessas escolas ainda se perpetuam pelo fato de oferecerem dentro da comunidade uma educação próxima das moradias dos alunos, principalmente das crianças que estudam no Ensino Fundamental, anos iniciais, sendo vistas por muitos como "um mal necessário". Outro enfrentamento das escolas multisseriadas é o número de alunos, que diminui cada vez mais devido à transferência destes para as escolas-polo.

O documento final do 2 o Seminário de Combate ao Fechamento de Escola no Campo realizado em 2019 na Universidade Federal do Pará, Campus de Castanhal, denuncia que só em 2017 foram fechadas 181 no Estado do Pará, dessas 126 localizadas no campo e 2.058 escolas foram paralisadas, 1.872 situadas no campo. Esse número elevado de fechamento das escolas do campo tem preocupado os movimentos sociais e demais envolvidos com a educação, pois as escolas multisseriadas são características da educação do campo, as quais por muito tempo não tiveram a atenção do poder público para garantir suas condições de funcionamentos de modo a garantir um ensino de qualidade.

Nesse sentido, destacamos a realidade do município de Igarapé-Miri para representar a experiência vivenciada na escola do campo. Para tanto ancoramo-nos em dados fornecidos pela Secretaria Municipal de Educação (Semed).

Os dados revelam que no ano de 2018 o município apresentou 60 turmas multisseriadas no Ensino Fundamental, das quais 59 estavam no campo; essas 59 turmas estavam distribuídas em 45 escolas, que em sua maioria são escolas conhecidas como "isoladas" por se caracterizarem como escolas com uma ou duas salas de aula, uma secretaria e cozinha. As outras turmas também se apresentam nos mesmos aspectos, mas devido aos processos de nucleação, identificam-se como turmas de uma escola-polo. Turmas da EJA multisseridas eram 17, das quais 15 estavam no campo e as turmas de ensino infantil multisseriadas eram 55 e todas estavam localizadas no campo. 
Isto significa que as turmas multisseriadas formam aproximadamente $20 \%$ das turmas presentes no meio rural do município, por isso é importante discutir essa modalidade de ensino que se faz muito presente na educação do campo em Igarapé-Miri e na Amazônia paraense.

No caso das comunidades ribeirinhas, as escolas multisseriadas geralmente são constituídas por uma sala de aula, secretaria, cozinha, localizadas às margens dos rios; elas ainda servem, em muitos casos, como hospedagem para os professores que não são da localidade. Essas escolas, quase sempre, são a única representação do Estado nas localidades e são também um ponto de referência que serve como espaço de reuniões e demais eventos que ocorrem nas comunidades rurais da Amazônia (OLIVEIRA, 2015).

\section{AS PRÁTICAS PEDAGÓGICAS NAS ESCOLAS MULTISSERIADAS}

O trabalho desenvolvido com as turmas multisseriadas nos provocam para apostas metodológicas que são transversalizadas pela compreensão de práticas multi e interdisciplinares, tendo como diretriz reflexiva o tema gerador sintonizado nos estudos freirianos. Para Freire (1987), o tema gerador deve ser elaborado a partir de elementos inter-relacionados à realidade, antes de se trabalhar a totalidade da questão; dessa maneira, busca-se abordar com os alunos o sentido e significado de comunidades tradicionais para que eles possam conhecer suas particularidades, antes de vê-los em sua conjuntura total.

Compreendemos que o temas geradores devem agir de maneira conscientizadora, levando os sujeitos envolvidos a superar o que Freire chama de "situações limites"; essas situações limites são apresentadas em nossa realidade para as pessoas como dificuldades ou barreiras a serem superadas para chegar a um determinado nível de humanização e é preciso que os sujeitos superem tais dificuldades, e a cada situação o limite seja superado. Essas dificuldades, em sua maioria, são impostas por contextos históricos.

Freire (1987) também ressalta que os temas geradores partem da diologicidade, quando o professor busca construir com os alunos, na perspectiva da realidade local e ainda diz "o que temos de fazer, na verdade, é propor ao povo, através de certas contradições básicas, sua situação existencial, concreta, presente, como problema que, por sua vez, o desafia e, assim, exige resposta, não só no nível intelectual, mas no nível de ação".

Dessa forma, os temas geradores devem ser elaborados de forma que façam os sujeitos pensarem sobre suas existências e suas posições na sociedade, tirando-os de suas opressões, não impondo nossa visão de mundo, porém ajudando-os a formar as suas próprias visões.

Os temas geradores nos permitem trabalhar de forma lúdica e dinâmica vários conteúdos dentro da sala de aula, interligando as diferentes séries de forma interdisciplinar, levando em consideração a realidade do aluno. Dessa forma é possível, por exemplo, em apenas uma atividade trabalhar os conteúdos de mais de uma série, envolvendo mais de uma disciplina e articulando teoria e prática. 
Severino (1998) alerta sobre o caráter fragmentado que a educação no Brasil apresenta, destacando que essa fragmentação é perceptível de várias formas: uma é a matriz curricular, que apresenta conteúdos específicos por disciplinas sem que haja uma integração entre eles; a outra está nas próprias prática dos professores que não conseguem articular a interação entre os conteúdos, como se cada disciplina apresentasse rumos divergentes uma da outra.

O autor então afirma que trabalhar de maneira interdisciplinar significa contrapor-se ao modelo fragmentado de ensino que foi sendo historicamente imposto a nós, mas que a interdisciplinaridade deve ser pensada de maneira sistemática e não de qualquer maneira, pois ela deve envolver o aluno e sua realidade. O caminho para isso é atuar de maneira coletiva, envolvendo escola e comunidade para que a prática pedagógica seja realmente de grande valia.

As práticas interdisciplinares do educando deve ser voltada para a construção de um sujeito que supere o estilo individual e passe a agir no coletivo para que possa se elevar na condição de cidadão que está dentro de uma sociedade e que possa exercer seus direitos; desse modo a interdisciplinaridade vai além de apenas unificar os fragmentos em uma totalidade, ligar o diferente, ou seja, a interdisciplinaridade integra o conhecimento científico com os valores expressados no cotidiano dos sujeitos.

Severino (1998, p. 42-43) destaca os seguintes pontos que devemos abordar nas práticas interdisciplinares:

- é sempre articulação do todo com as partes;

- é sempre articulação dos meios com os fins;

- é sempre em função da prática, do agir. O saber solto fica petrificado, esquematizado, volatilizado;

- precisa sempre ser conduzido pela força interna de uma intencionalidade;

- a prática do conhecimento só pode se dar, então, como construção dos objetos pelo conhecimento; é fundamentalmente prática de pesquisa;

- aprender é, pois, pesquisar para construir; constrói-se pesquisando.

Junto com a interdisciplinaridade deve-se também trabalhar a dialogicidade. Freire (1987), em sua obra Pedagogia do Oprimido, ressalta a importância da dialogicidade no processo de ensinar e aprender, pois tal prática é essencial para o não esgotamento de ambos, educando e educador, na dinâmica em sala de aula, pois por meio do diálogo é gerada a ação mais reflexão, que resulta na práxis dentro do ambiente escolar.

O diálogo em sala de aula possibilita a escuta do sujeito, o qual, muitas vezes, é visibilizado na sociedade, em casa, na escola, entre muitos outros ambientes. Esse diálogo gera um profundo comprometimento entre os sujeitos envolvidos. Freire (1987, p. 45) ressalta que:

Sendo fundamento do diálogo, o amor é, também, diálogo. Daí que seja essencialmente tarefa de sujeitos e que não possa verificar-se na relação de dominação. Nesta, o que há é patologia de amor: sadismo em quem domina, masoquismo nos dominados. Amor, não, porque é um ato de coragem, nunca de medo, o amor é um 
compromisso com os homens. Onde quer que estejam estes, oprimidos, o ato de amor está em comprometer-se com a sua causa. A causa de sua libertação. Mas, este compromisso, porque é amoroso, é dialógico.

Diante disso, o diálogo torna-se essencial para uma educação libertadora e emancipatória, em que as vozes são ouvidas, pois possibilita ao educando entender sua realidade como sujeito e, quando há comprometimento, em busca de devidos auxílios por meio de suas práticas pedagógicas.

Para que haja diálogo é necessário que os sujeitos se vejam em igualdade, onde não há inferiores e/ou superiores, ninguém é detentor da razão e do saber, todos se igualam e tornam o processo, o diálogo como essencial. Acima de tudo é necessário que acredite na mudança e superação do homem e em sua capacidade de se reinventar.

Freire (1987) continua instruindo que, para que aconteça a dialogicidade dentro da sala de aula, o educador precisa se questionar sobre o que deve dialogar em paralelo com os conteúdos programáticos, de maneira que não seja imposta aos alunos uma gama de conhecimentos desconexos, mas com conhecimentos organizados que venham acrescentar na vida dos educandos. Isso nos permite também construir uma educação de acordo com a realidade local, diferente quando o educador já leva suas aulas baseadas em visões gerais sobre os sujeitos envolvidos, o que resulta em equívocos e não eficiências em suas atividades.

Quando se trata das escolas multisseriadas ribeirinhas, essas práticas pedagógicas ficam mais ricas quanto a detalhes, por isso Santos (2017) nos alerta quando observa que os ribeirinhos, como sujeitos amazônidas, possuem uma ligação estreita com os rios, a terra e a floresta, tendo uma forte ligação com o meio ambiente, onde estabelecem seu território. Seus trabalhos e sobrevivência vêm do rio, da terra e das florestas e conhecer essa realidade é extremamente necessária para a construção de práticas pedagógicas que venham transformar, de maneira positiva, a vida do ribeirinho.

As turmas multisseriadas ainda apresentam a heterogeneidade que, de acordo com Freitas (2010), é importantíssimo para a dinâmica de aprendizagem dos alunos, pois no fluxo interativo de conhecimentos que se estabelece entre professor-aluno e aluno-aluno pode possibilitar a construção de múltiplas maneiras de se compreender os conhecimentos trabaIhados. Desse modo, os alunos deixam de ser apenas ouvintes e passam a ser críticos do conhecimento, eles vivenciam de maneira diferenciada o conteúdo trabalhado e o professor atua como mediador do conhecimento, o que nos mostra a relevância da produção do conhecimento nas turmas multisseriadas, para a construção de prática educacional heterogênea.

Para dar conta desta diversidade nossa principal preocupação quando se fala em ministrar aula em uma turma multisseriada seria como expor diferentes conteúdos e com várias séries dentro de uma única sala ao mesmo tempo. Sobre isso, destacamos dois pontos: primeiro destacamos as dificuldades para expor vários conteúdos, o que ocorre principalmente por não haver um currículo específico, com temas determinados, para trabalhar com as turmas multisseriadas, sendo entregue aos professores os conteúdos programáticos de cada turma separadamente. Isso já acaba gerando no professor a ideia de que ele precisa separar cada série com seus respectivos conteúdos. 0 segundo ponto trata-se de várias séries dentro de uma única sala de aula ao mesmo 
tempo; nossa vivência tem mostrado que isto acontece quando não se explora o multi, o perfil heterogêneo e diverso da turma, ou seja, quando as práticas pedagógicas não são voltadas para o coletivo (MORAES et al., 2010).

$\mathrm{Na}$ perspectiva de repensar as práticas pedagógicas nas escolas multisseriadas procuramos como professor-pesquisador romper com as práticas disciplinares que historicamente estiveram presentes na vida dos sujeitos do campo sem que suas especificidades fossem de fato atendidas.

Nesse sentido, repensamos todas as atividades desenvolvidas como parte prática dos conteúdos programáticos na área de Ciências da Natureza e Ciências Humanas (História e Geografia) como atividades avaliativas. Para isso realizamos roda de conversa com os alunos, ocasião em que foi percebido que a comunidade tinha uma forte ligação com a agricultura, porém pouco conheciam sobre os campesinos e os povos tradicionais da Amazônia. Hage (2018) afirma que as populações ribeirinhas são as mais específicas da Amazônia, pois são uma construção única desta região, constituída a partir de muitos povos, como imigrantes, negros africanos, nordestinos, entre outros.

Estes sujeitos criaram suas grandes especificidades com a floresta, as águas e a terra, travando lutas para a afirmação de suas identidades como povo da floresta, colocados como protagonistas nas discussões de suas culturas, natureza e trabalho.

Deste modo, Borges e Silva (2012, p. 214) afirmam que:

A educação do campo deve trabalhar os processos de percepção e de formação de identidades, fazendo que a pessoa tenha a visão de si mesma (autoconsciência) e social, ou melhor, veja-se como camponês, trabalhador, gênero, cultura, etc., em uma perspectiva coletiva.

Nesse viés, foram trabalhados os conteúdos voltados para tais temáticas que viessem reafirmar a identidade e a realidade dos sujeitos. E para o fim das discussões dos conteúdos foram propostas as aulas práticas, nas quais se relacionavam os conteúdos com alguma prática voltada àquele assunto.

No momento em que se realizou o levantamento inicial da realidade dos alunos sobre comunidades tradicionais, alguns questionamentos foram feitos nas aulas para a escolha dos temas trabalhados. Nessa ocasião identificou-se uma visão extremamente negativa em relação aos indígenas e quilombolas, além da dificuldade de se afirmarem num pertencimento como sujeito ribeirinho, pescador e agricultor familiar. Estes levantamentos possibilitaram a construção dos planos de aula a serem trabalhados.

Nos Quadros 1 e 2 temos os conteúdos que foram abordados em sala de aula relacionados às disciplinas de História, Geografia e Ciências, os quais eram correlacionados em aulas integradas por meio de temas geradores.

A partir deste diagnóstico inicial foi possível escolher quais temas trabalhar com os alunos nos conteúdos das disciplinas de História e Geografia. Para a escolha dos temas a serem trabalhados nos assuntos de Ciências foi levada em consideração a realidade da comunidade para se construir a problemática a ser anunciada e intensificada na atuação docente.

$\mathrm{Na}$ escuta realizada a partir do diálogo com os alunos, identificou-se que os moradores da comunidade são policultores, pois trabalham com agricultura, pesca, comércio, entre outras atividades, e que ainda que produzissem uma parte de sua alimen- 
tação, eles compravam a maioria no centro urbano do município. Essas informações foram essenciais para a construção dos temas geradores que seriam trabalhados com os alunos.

Dentro das turmas multisseriadas os temas geradores são práxis que podem nos ajudar, como professores, a trabalhar o coletivo. Esses temas geradores podem ser usados de maneiras diversas, como jogos, brincadeiras, atividades práticas, entre outros.

Segundo Miranda e Brick (2017), sob a concepção freiriana, são elencados passos para elaboração de um tema gerador, que são: fazer um levantamento da realidade local, descobrir a situação-problema a ser discutida, roda de conversa com a comunidade para explanar as possíveis problemáticas a serem trabalhadas, a escolha do tema para se trabalhar em sala de aula e aplicar os temas junto com os conteúdos.

Os conteúdos foram assim trabalhados, após uma explanação pontuando as principais especificidades de cada conteúdo. Em cada semestre os conteúdos foram tratados de maneiras separadas, em cada disciplina (Quadros 1 e 2 ), quando suas propriedades foram trabalhadas antes de serem correlacionadas em atividades.

Quadro 1 - Conteúdos de Ciências trabalhados por bimestres e suas respectivas atividades

\begin{tabular}{|c|c|l|}
\hline \multicolumn{3}{|c|}{ CONTEÚDOS DE CIÊNCIAS TRABALHADOS POR BIMESTRE } \\
\hline Bimestre & Conteúdos & \multicolumn{1}{c|}{ Atividades Práticas } \\
\hline $1^{\circ}$ bimestre & Seres vivos e não vivos & Aula exploratória: seres vivos e não vivos ao redor da escola. \\
\hline $2^{\circ}$ bimestre & Seres vivos animais & $\begin{array}{l}\text { Observação de caixa entomológica: variedade de formas, } \\
\text { cores e tamanhos dos seres vivos. }\end{array}$ \\
\hline $3^{\circ}$ bimestre & Seres vivos vegetais & O nascer das plantas: germinação de sementes. \\
\hline $4^{\circ}$ bimestre & Ecossistemas & Observação de decompositores e polinizadores. \\
\hline
\end{tabular}

Fonte: Acervo da Pesquisa, 2018.

Quadro 2 - Conteúdos de História e Geografia trabalhados por bimestres e suas respectivas atividades

\begin{tabular}{|c|c|l|}
\hline \multicolumn{3}{|c|}{ CONTEÚDOS DE HISTÓRIA E GEOGRAFIA TRABALHADOS POR BIMESTRE } \\
\hline Bimestre & Conteúdos & \multicolumn{1}{c|}{ Atividades Práticas } \\
\hline $1^{\circ}$ bimestre & Comunidades Ribeirinhas & Roda de conversa: como é onde eu moro? \\
\hline $2^{\circ}$ bimestre & Comunidades Indígenas & Construção de mandalas usando sementes. \\
\hline $3^{\circ}$ bimestre & Comunidades Quilombolas & Confecção de Abayomis. \\
\hline $4^{\circ}$ bimestre & $\begin{array}{c}\text { Influências das Comunidades } \\
\text { Tradicionais na Cultura } \\
\text { Brasileira }\end{array}$ & $\begin{array}{l}\text { Seminário: O que você usa na sua comunidade que } \\
\text { é influência dos africanos, indígenas e portugueses? }\end{array}$ \\
\hline
\end{tabular}

Fonte: Acervo da Pesquisa, 2018.

Foram discutidos no primeiro bimestre as comunidades ribeirinhas e suas formações no espaço amazônico e os seres vivos e não vivos que lá existem, quando os alunos foram questionados sobre os seres vivos e não vivos que influenciam no dia a dia dos ribeirinhos; eles elaboraram uma lista com tais itens e falavam de sua importância no seu cotidiano. 
Os pais, nas entrevistas, ressaltaram ser importante trabalhar com as crianças sobre suas origens e suas identidades, porém outros, por terem pouca compreensão sobre a construção de suas identidades, destacam que a escola deve focar no que eles classificam como conteúdo, conforme pode ser confirmado nos depoimentos:

Pai 1 - A escola não deve se preocupar com isso, a gente que deve ensinar.

Pai 2 - (...) eles aprendem nossos costumes eu sou do tempo antigo e sei muita coisa. Sim, a escola deve ensinar.

Pai 3 - Eu não acho que é importante a escola ensinar, isso eu ensino pra ela, na sala de aula é mais importante o conteúdo.

Pai $4-(\ldots)$ aqui a gente usa muito remédio caseiro e eu acho que sim (a escola deve ensinar).

Isso reforça a concepção de uma ideia educacional voltada para atender às necessidades do capitalismo e não para a promoção do sujeito como ser social, entretanto criou-se em seus hábitos e costumes a reprodução da visão colonialista e de ensino centrado numa escola tradicional.

No segundo bimestre foram trabalhados os conteúdos de História, Geografia e Ciências, considerando a realidade das comunidades indígenas, como eles já ocupavam a Amazônia e seres vivos animais, respectivamente em cada disciplina, e posteriormente relacionando os conteúdos em uma atividade prática. Foi trabalhada com os alunos a relação dos indígenas com seres vivos flora/fauna, e como trabalho final foram feitas mandalas, arte indígena, com sementes, em que os alunos representavam nelas algo que haviam aprendido, pintando as sementes de acordo com os significados das cores para os indígenas.

No terceiro bimestre foram trabalhados em História, Geografia e em Ciências as comunidades quilombolas, relação dos continentes americano e africano e seres vivos vegetais. Após uma abordagem sobre tais temas, foi feita uma atividade a partir de tal questionamento: Como se dá a produção da agricultura nas comunidades quilombolas? Foi discutida a história dos negros no Brasil, suas formações e importância para nossa sociedade atual; como aula prática foram produzidas as Abayomis, que são bonecas feitas com retalhos de tecidos, em que o corpo é confeccionado em tecido preto que atualmente representa as mães negras e que, no período da escravidão, eram feitas pelas mães escravas com pedaços de suas roupas para seus filhos brincarem, constituindo hoje, também, um símbolo de amor e cuidado.

Quanto a essa atividade, muitos alunos retornaram de suas casas com as Abayomis, em razão de seus pais não aceitarem alegando que se tratava de "bonecas de macumba". Isso nos remete para as dificuldades de trabalhar a Lei 10.639/2003 e a Lei $11.645 / 2008$, que incluem no currículo oficial a obrigatoriedade de trabalhar a temática "Histórica e Cultura Afro-Brasileira e Indígena" nas escolas de Educação Básica. As posturas dos pais apresenta os vestígios da catequese colonial que demonificou as religiões afro-brasileiras não cristãs. Muitos alunos, entendendo o significado das Abayomis a partir das reflexões levantadas nas aulas em que houve fortemente o destaque para os aspectos históricos e culturais, não quiseram jogar fora e entregaram ao professor. 
Ao observarmos o trabalho na produção familiar identificamos os destaques direcionados às atividades sobre como germinar as sementes para além de leguminosas e decorativas. Essas sementes e galhos de plantas foram trazidos pelos alunos e, sob a orientação de um agrônomo, fizemos o processo de germinação das sementes e enraizamento dos galhos.

Foram usados para a germinação das plantas resíduos plásticos trazidos pela maré, como: garrafas pet, potes de creme de cabelo, baldes e depósitos danificados, potes de manteiga, entre outros, que são considerados inutilizáveis e despejados nos rios. Como o rio Ana Igarapé apresenta a dinâmica de maré (enchente e vazante) torna-se inviável a plantação direta no solo, desta forma foi sugerido aos alunos reutilizarem esses resíduos plásticos para a construção de uma horta suspensa. Sobre essa prática pedagógica houve uma aceitação positiva por parte dos pais. Quando questionados sobre essa atividade eles apresentaram as seguintes opiniões:

Pai 1 - Foi muito bom, até hoje ele tem o pé de quiabo que trouxe de lá.

Pai 2 - Eles gostaram muito, eles plantaram o que trouxeram de lá, mas a chuva e as galinhas comeram (...) o senhor foi o primeiro que deu uma aula diferente, onde os alunos levaram uma planta para a aula, eu até achei estranho, mas depois eu vi que tinha um objetivo.

Pai 3 - Eu acho importante porque vai ajudar o pai e a mãe na cozinha e eles aprendem a plantar flores pra decorar a casa e no caso desses (hortaliças) pra pôr na comida, isso incentiva eles.

Pai 4 - Acho importante, eles me ajudam em casa com isso.

No quarto bimestre foram trabalhadas em História, Geografia e Ciências as influências das comunidades tradicionais na cultura brasileira e ecossistemas, inter-relacionando os conteúdos. Por meio de seminário, os alunos apresentaram as influências deixadas na sociedade contemporânea, em específico nas comunidades ribeirinhas, e o envolvimento deles com o meio ambiente. Isso levou-os a refletirem sobre a culinária, artesanato, dança, vocabulário, trabalho, entre outros aspectos socioculturais que formam suas identidades e que foram repassados pelos indígenas, quilombolas e portugueses.

No conteúdo de ecossistemas foi discutida também a importância da preservação do meio ambiente para as comunidades tradicionais devido as suas importantes relações com a natureza. Como no terceiro bimestre foram recolhidos resíduos sólidos trazidos pelas águas, foi trabalhada a conscientização ambiental, explanando as possíveis consequências da poluição das águas e das florestas para aqueles que dependem diretamente delas.

Todas essas práticas foram desenvolvidas a partir dos diálogos que foram realizados com os alunos para reconhecer suas necessidades sociais e os seus cotidianos e relacioná-los com os conteúdos trabalhados nas disciplinas de Ciências, História e Geografia, ou seja, de maneira interdisciplinar, levando os estudantes a se envolverem de maneira direta com as atividades desenvolvida em sala de aula.

Tomando como base as reflexões de Paulo Freire (1987), este destaca a importância de construir junto com os educandos a didática dos conteúdos que serão trabalhados em sala de aula. O autor afirma que a educação deve ser emancipatória e libertado- 
ra, mas essa educação só acontece se ela for participativa, ou seja, quando não se tem o detentor de conhecimento e o receptor de conhecimento, mas sim quando há a troca mútua de conhecimento e saberes entre educador e educando.

\section{CONSIDERAÇÕES FINAIS}

Em razão dos fatos mencionados, conclui-se que dentro de uma sala multisseriada o que faz a diferença no aproveitamento das práticas do professor é organizar os alunos de forma que possam trabalhar de maneira integrada e heterogênea, pois essa é uma especificidade que essa modalidade de ensino oportuniza e que deve ser aproveitada pelo professor para a melhoria da dinâmica no processo de organização e de ensino e aprendizagem.

Identificamos que o tema gerador e a dialogicidade são caminhos políticos, pedagógicos e metodológicos que nos permitem conhecer a realidade dos alunos para que possam participar mais ativamente das atividades propostas, proporciona uma relação entre educando, educador e o conhecimento a ser trabalhado e vivenciado na realidade local e global, os quais ajudaram os alunos no enfrentamento de suas problemáticas, revendo suas visões de mundo e conquistando suas posições na sociedade.

No final do ano letivo ficou evidente nos alunos as mudanças e a assimilação dos conhecimentos adquiridos quanto as suas identidades e as comunidades campesinas. Foi percebido em suas falas que para ser ribeirinho deve-se afirmar seus modos de vida demarcados por territórios e territorialidades como marcos da existência e da r-existência para a produção de sua sociabilidade (GONÇALVES, 2015).

Desenvolver práticas pedagógicas construídas com os sujeitos do campo voltadas para a afirmação da identidade e construção da autonomia dos educandos é de extrema importância para os sujeitos ribeirinhos, pescadores, agricultores, quilombolas, extrativistas e indígenas, visto que muitos vivem sem perspectivas para uma vida de qualidade e excluídos socialmente e nós como professores podemos ser os agentes de transformação para essas famílias, por meio de uma educação transformadora.

A educação, para muitos, é a única perspectiva positiva para alcançar uma meIhor qualidade de vida e quando se trata dos sujeitos do campo ela se torna símbolo de esperança ainda maior, uma vez que eles vivem, em sua maioria, marginalizados pela sociedade hegemônica. Fornecer uma educação de qualidade para as escolas no campo significa se contrapor à opressão que historicamente vem submetendo os camponeses a uma vida insatisfatória, voltada para uma construção capitalista que busca apenas para formá-los como mão de obra.

Assim, apostamos em práticas pedagógicas de perspectiva contra-hegemônica para constribuir com a formação de sujeitos críticos dentro das comunidades nas quais atuamos como docentes. Trabalhar a dialogicidade, a interdisciplinaridade, os temas geradores, é uma possibilidade de proporcionar, no contexto da sala de aula, a perspectiva crítica e a ação nas pessoas do campo para lutarem por seus direitos e por igualdade social. 
As escolas multisseriadas são características do campo e também são únicas por apresentarem uma particularidade, a heterogeneidade, fator que muitas vezes é rejeitado devido à soberania do modelo seriado de ensino.

Finalizamos afirmando que trabalhar com a diversidade é potencializar as trocas de experiências entre os sujeitos do conhecimento; dessa forma devemos permitir que se estabeleça um fluxo de conhecimentos e trocas de experiências entre todos os sujeitos envolvidos com o processo de ensino e aprendizagem.

\section{REFERÊNCIAS}

ARROYO, Miguel Gonzalez. Outros sujeitos, outras pedagogias. 2. ed. Petrópolis, Rio de Janeiro: Vozes, 2014.

BORGES, Heloisa da Silva; SILVA, Helena Borges. A educação do campo e a organização do trabalho pedagógico. In: GHEDIN, Evandro (org.). Educação do campo: epistemologias e práticas. São Paulo: Cortez, 2012.

BRASIL. Ministério da Educação. Decreto № 7.352, de 4 de novembro de 2010. Dispõe sobre a política de educação do campo e o Programa Nacional de Educação na Reforma Agrária- PRONERA. Diário Oficial da União, Brasília, 2010.

BRASIL. Resolução no 01, de 03 de abril de 2002. Diretrizes Operacionais para Educação Básica nas Escolas do Campo. Brasília: CNE; CEB, 2002.

FERNANDES, Bernado Mançano; MOLINA, Mônica Castagna. O campo da educação do campo. 2004. Disponível: http://www2.fct.unesp.br/nera/publicacoes/ArtigoMonicaBernardoEC5.pdf. Acesso em: 20 jul. 2019.

FREIRE, Paulo. Pedagogia do oprimido. 17. ed. Rio de Janeiro: Paz e Terra, 1987.

FREITAS, Maria Natalia Mendes. Heterogeneidade: fios e desafios da escola multisseriada da ilha de Urubuoca. In: ROCHA, Maria Isabel Antunes; HAGE, Salomão Mufarrej. Escola de Direito: reinventando a escola multisseriada. Belo Horizonte: Autêntica, 2010.

GONÇALVES, Carlos Walter Porto. Amazônia, Amazônias. 3.ed. São Paulo: Contexto, 2015.

HAGE, Salomão Antônio Mufarrej. Transgressão do paradigma da (Multi)Seriação como referência para a construção da escola pública do campo. Educação e Sociedade, Campinas, v. 35, n. 129, p. 1.165-1.182, out./dez., 2014. Disponível em: https://www.scielo.br/pdf/es/v35n129/0101-7330-es-35-129-01165.pdf. HAGE, Salomão Antônio Mufarrej. Trabalho, natureza e cultura como referência para a construção da escola pública do campo na Amazônia. Projeto Universal do CNPq, 2018.

HAGUETTE, Teresa Maria Frota. Metodologias qualitativas na sociologia. Petrópolis: Vozes, 2005.

MIRANDA, Valdoilson da Cruz de; BRICK, Elizandro Maurício. O Ensino de Ciências da Natureza e Matemática e a perspectiva freiriana na Escola do Campo: reflexões sobre uma experiência no Assentamento Antonio Conselheiro, Barra do Bugres/MT. In: MOLINA, Mônica Castagna. Licenciaturas em Educação do Campo e o ensino de Ciências Naturais: desafios à promoção do trabalho docente interdisciplinar. Brasília: Editora Universidade de Brasília, 2017.

MORAES, Edel; BARROS, Oscar Ferreira; HAGE, Salomão Mufarrej; CORRÊA, Sérgio Roberto Moraes. ROCHA, Maria Isabel Antunes; HAGE, Salomão Mufarrej. Transgredindo o paradigma (multi)seriado nas escolas do campo. In: Escola de Direito: reinventando a escola multisseriada. Belo Horizonte: Autêntica Editora, 2010.

OLIVEIRA, Sávio Bicho de. Os ribeirinhos da Amazônia: das práticas em curso à educação escolar. Revista de Ciências da Educação, Americana, SP: Unisal, a. XVII, n. 32, p. 73-95, jan./jun. 2015.

OLIVEIRA NETO, Rodolfo. Educação popular do campo e território: uma análise da prática educativa do Getepar-NEP na Amazônia ribeirinha. 2011. Dissertação (Mestrado em Educação) - Universidade do Estado do Pará, Centro de Ciências Sociais e Educação, Belém, 2011.

PEREIRA, Edir Augusto Dias. As encruzilhadas das territorialidades ribeirinhas: transformações no exercício espacial do poder em comunidades ribeirinhas da Amazônia Tocantina Paraense. 2014. Tese (Doutorado em Geografia) - Universidade Federal Fluminense, Instituto de Geociências, Rio de Janeiro, 2014.

PEREIRA, Edir Augusto Dias. O campo ribeirinho: educação escolar e território na Amazônia. In: SOUZA, Dayana Viviany Silva de; VASCONCELOS, Maria Eliane de Oliveira; HAGE Salomão Antônio Mufarrej (org.). Povos ribeirinhos da Amazônia: educação e pesquisa em diálogo. Curitiba: CRV, 2017. 
SANTOS, Jenijunio dos. A formação do povo ribeirinho no contexto da Amazônia brasileira. In: SOUZA, Dayana Viviany Silva de; VASCONCELOS, Maria Eliane de Oliveira; HAGE Salomão Antônio Mufarrej (org.). Povos ribeirinhos da Amazônia: educação e pesquisa em diálogo. Curitiba: CRV, 2017.

SEVERINO, Antônio Joaquim. Conhecimento pedagógico e a interdisciplinaridade: o saber como intencionalização da prática. In: FAZENDA, Ivani Catarina Arantes (org.). Didática e interdisciplinaridade. Campinas, SP: Papirus, 1998.

SOUZA, Maria Antônia de. Práticas pedagógicas e elementos articuladores. Curitiba: Universidade do Tuiuti do Paraná, 2016.

SOUZA, Maria Antônia de. Educação do campo: políticas, práticas pedagógicas e produção científica. Revista Educação e sociedade, Campinas, v. 29, n. 105. p. 1.086-1.111, set./dez. 2008.

THIOLLENT, Miguel. Metodologia da pesquisa-ação. São Paulo: Cortez; Autores Associados, 1986.

UFP. Universidade Federal do Pará. Seminário de Combate ao Fechamento de Escolas no Campo no Estado do Pará, II. Documento final. Castanhal: Universidade Federal do Pará, 2019.

VASCONCELOS, Maria Eliane de Oliveira; HAGE, Salomão Antonio Mufarrej. Memórias do Movimento de Ribeirinhos e Ribeirinhas no Amazonas: contribuições para uma educação dialógica. In: SOUZA, Dayana Viviany Silva de; VASCONCELOS, Maria Eliane de Oliveira; HAGE Salomão Antônio Mufarrej (org.). Povos ribeirinhos da Amazônia: educação e pesquisa em diálogo. Curitiba: CRV, 2017. 